\title{
Aplikasi Teknologi Penetasan Dalam Rangka Peningkatan Populasi Ternak Itik Di Kecamatan Simbang Kabupaten Maros Provinsi Sulawesi Selatan
}

\author{
Daryatmo, M. Rachman Hakim, Wempie Pakiding \\ Departemen Produksi Ternak Fakultas Peternakan Universitas Hasanuddin, Makassar \\ Email: daryatmo@unhas.ac.id
}

\begin{abstract}
Abstrak - Program pengabdian masyarakat ini bertujuan untuk meningkatkan pengetahuan dan keterampilan masyarakat peternak itik di Kabupaten Maros terutama dalam aspek penetasan. Kegiatan pengabdian dimulai dengan tahapan sosialisasi untuk mengidentifikasi masalah yang berada di bawah pengawasan, mengamati pelatihan dan pendampingan, dan kegiatan pasca capaian. Melalui tahapan kegiatan pelatihan, pengabdi bersama dengan peternak menerapkan seleksi telur tetas yang baik, penerapan penetasan telur dengan menggunakan mesin tetas dan diikuti dengan penanganan anak itik pasca menetas. Tingkat partisipasi dalam kegiatan cukup tinggi, dengan partisipasi seluruh peternak selama kegiatan pengabdian. Diharapkan kegiatan ini meningkatkan populasi ternak sehingga pendapatan peternak dapat diperbaiki serta memperbaiki kesejahteraan masyarakat. Selain itu kegiatan pengabdian masyarakat yang telah dilakukan menunjang program pemerintah daerah dalam mengembangkan populasi ternak itik di wilayah Kecamatan Simbang Kabupaten Maros.
\end{abstract}

Kata Kunci: Ternak itik, teknologi penetasan, Maros

\begin{abstract}
The purpose of this community partnership program were to provided the knowledge and skills of duck breeder communities in Maros Regency, especially in the hatchery aspect. Community service activities begin with a socialization stage to identify problems under supervision, observe training and mentoring, and post achievement activities. Through the stages of training activities, the service provider together with the breeders implements good hatching egg selection, applies the hatching of eggs using a hatching machine and is followed by handling post-hatch ducks. The level of participation in activities is quite high, with the participation of all breeders during service activities. It is hoped that this activity will increase the livestock population so that the income of breeders can be improved and improve the welfare of the community. In addition, community service activities that have been carried out support local government programs in developing duck livestock populations in the Simbang District, Maros Regency.
\end{abstract}

Keywords: Ducks, hatching technology, Maros

\section{PENDAHULUAN}

Ternak itik merupakan salah satu ternak yang banyak dibudidayakan oleh masyarakat di pedesaan. Meningkatnya permintaan akan produk dari ternak itik merupakan potensi yang masih dapat di kembangkan. Untuk memenuhi permintaan telur dan daging itik yang semakin meningkat maka diperlukan upaya untuk meningkatkan produktifitas ternak itik yang sekarang ini masih tergolong sangat rendah.. Umumnya pemeliharaan itik merupakan masih bersifat tradisional sehingga produktifitasnya masih rendah.

Usaha peternakan mitra masih mengandalkan pakan alami yang ada di sekitar sungai dan sawah. Pemberian pakan dedak di berikan sekali sehari selanjutnya ternak itik di gembalakan di sekitar sungai dan sawah yang ada di daerahnya. Populasi yang mereka miliki masih sedikit karena sulitnya mendapatkan bibit.
Pengadaan bibit mereka dapatkan dengan menetaskan sendiri dengan menggunakan entok untuk mengerami sehingga tingkat keberhasilannya masih rendah.

Manajemen pemeliharaan ternak itik dapat mempengaruhi kualitas telur tetas. Hal ini akan mempengaruhi kualitas bibit yang akan dihasilkan. Selain hal tersebut manajemen penetasan juga mempengaruhi keberhasilan dalam usaha pengadaan bibit untuk dapat meningkatkan populasi ternak itik yang dimiliki. Penggunaan mesin tetas dapat membantu meningkatkan keberhasilan penetasan telur itik. Dengan penggunaan teknologi mesin tetas otomatis dapat meningkatkan produksi bibit ternak itik yang memiliki kualitas yang baik dan dalam jumlah yang mencukupi kebutuhan dari peternak.

Pemilihan lokasi mitra berdasarkan hasil suvei tim peneliti dan diskusi dengan beberapa 
peternak yang ada di daerah mitra. Dari hasil tersebut diketahui bahwa di lokasi mitra selain masih rendahnya populasi ternak itik yang mereka miliki dan pengadaan bibit masih dilakukan proses penetasan dengan menggunakan entok yang mengerami telur tetas itik.

Oleh karena itu, diperlukan suatu upaya untuk meningkatkan kapasitas pengelolaan usaha peternak agar dapat meningkatkan populasi ternak yang dipelihara. Pengabdian masyarakat dilakukan pada kelompok peternak dari keluarga miskin penerima bantuan sosial dengan sasaran utama mengatasi permasalahan pada aspek teknis pemeliharaan ayam kampung terutama aspek penetasan dan pengelolaan pasca tetas, melalui introduksi teknologi penetasan.

\section{MATERI DAN METODE PELAKSANAAN}

Ipteks yang diaplikasikan dalam program meliputi pembuatan mesin tetas, manajemen pengoperasion mesin tetas. Metode yang digunakan adalah: pelatihan, diskusi, ceramah, learning by doing, leaflet yaitu metode pendekatan massal, brosur sebagai metode pendekatan kelompok, metode pendekatan perorangan/individual (kunjungan), observasi, pendampingan, penyuluhan dan kombinasi berbagai metode [1]. Materi yang disampaikan dalam penyuluhan dan pelatihan adalah permasalahan penetasan dan pengelolaan pasca tetas yang dihadapi peternak. Kegiatan dilaksanakan pada bulan Juli hingga Nopember 2019 bertempat di Kecamatan Simbang Kabupaten Maros. Khalayak sasaran kegiatan pengabdian masyarakat adalah kelompok peternak itik di Kecamatan Simbang dengan jumlah kepala keluarga sasaran sebanyak 30 orang.

\section{HASIL DAN PEMBAHASAN}

Kegiatan utama pengabdian masyarakat dalam upaya meningkatkan keterampilan dan kapasitas usaha peternak itik di Kecamatan Simbang adalah kegiatan pelatihan yang menghadirkan peternak dari kelompok mitra dengan pemateri yang merupakan dosen dari Fakultas Peternakan Universitas Hasanuddin. Kegiatan yang berlangsung selama satu hari di rumah ketua kelompok mitra di Desa Simbang Kecamatan Simbang Kabupaten Maros, diikuti dengan antusias oleh seluruh peserta. Materi pelatihan yang diberikan meliputi kegiatan pembuatan mesin tetas, teknis penetasan dengan menggunakan mesin tetas sederhana, dan penanganan anak itik pasca tetas.

Capaian utama kegiatan pelatihan tentang pembuatan mesin tetas adalah peserta dapat membuat sendiri mesin tetas sederhana yang dapat dipergunakan dalam proses penetasan telur itik. Fokus materi diarahkan pada pengetahuan akan prinsip dasar pembuatan mesin tetas dan komponen komponen yang ada dalam mesin tetas serta fungsinya. Selanjutnya materi ini juga untuk meningkatkan kemampuan peternak dalam melakukan pembuatan dan perakitan komponenkomponen mesin tetas hingga menjadi mesin tetas yang dapat dipergunakan dalam proses penetasan [2]. Berdasarkan hasil kegiatan, peserta yang sudah memiliki kemampuan dasar dalam bidang pertukangan kayu sudah dapat membuat dan merakit komponen komponen mesin tetas sehingga dengan tambahan keterampilan ini, peternak dapat membuat sendiri mesin tetas yang akan dipergunakan sendiri maupun untuk dijual kepada peternak yang lain.

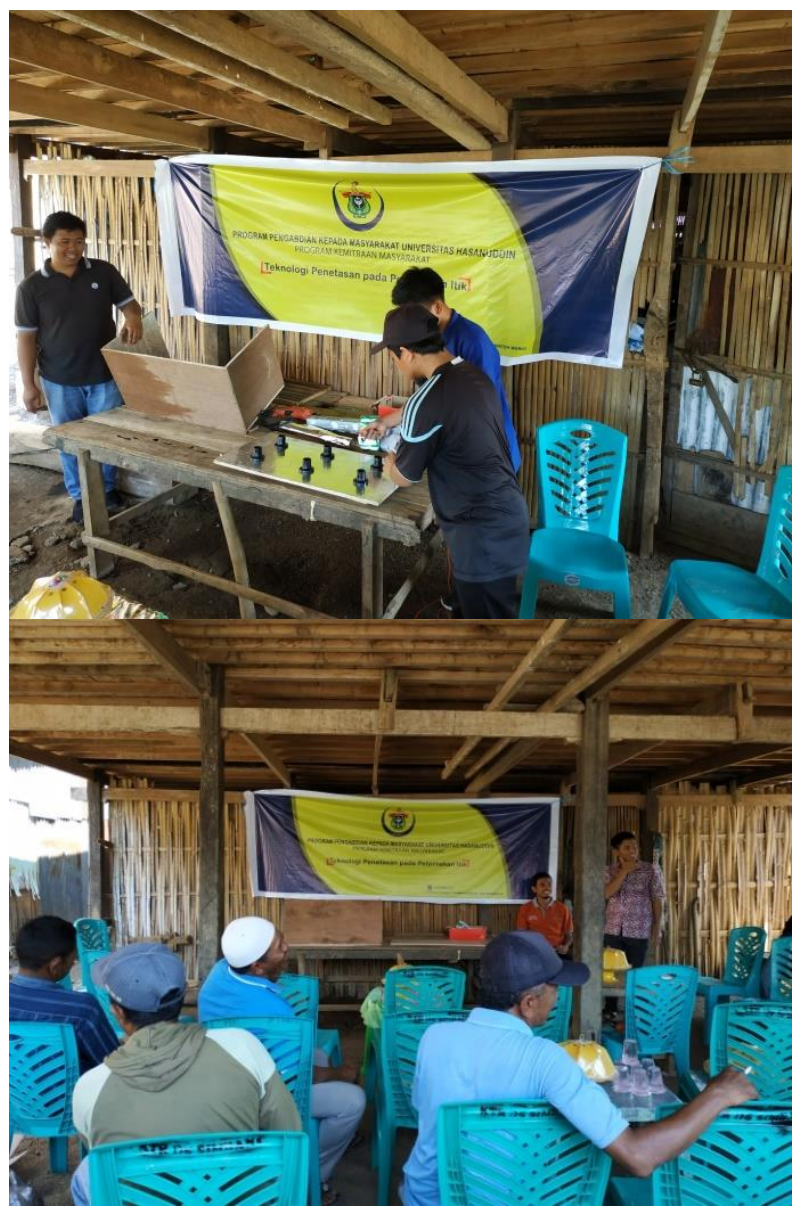

Gambar 1. Kegiatan Pelatihan Pembuatan Mesin Penetasan Pada Peternak Itik

Materi tentang teknologi penetasan difokuskan pada beberapa aspek penting diantaranya: seperti cara seleksi telur tetas. Pada materi ini peternak diperkenalkan cara memiliih telur tetas sampai pada proses sebelum dimasukkan ke dalam mesin tetas. Setelah itu peternak diberikan materi tentang prinsip kerja mesin tetas sederhana dan proses tatalaksana penetasan yang berlangsung selama 28 hari dengan suhu $37^{\circ} \mathrm{c}-38^{\circ} \mathrm{c}$ dengan kelembaban $80-85 \%$. Kegiatan penetasan dimulai 
dari penanganan telur yang baik selama dalam mesin tetas, seperti pembersihan telur, pembalikan/pemutaran telur, dan peneropongan telur untuk melihat fertilitas telur tetas.

Materi tentang bobot telur sangat penting karena bobot telur yang terlalu besar atau terlalu kecil menyebabkan menurunnya daya tetas [3]. Pemutaran telur yang dilakukan peternak selama proses penetasan sebanyak dua kali/hari. Proses pemutaran telur yang tidak teratur dapat menyebabkan panas yang mengenai telurmenjadi tidak merata sehingga embrio akan lengket pada kerabang dan akhirnya menyebabkan kematian embrio [4]. Dengan materi ini, terdapat peternak yang mengetahui dengan baik cara kerja mesin tetas bahkan memiliki kemampuan untuk mengoperasikan mesin tetas yang telah dibuat.

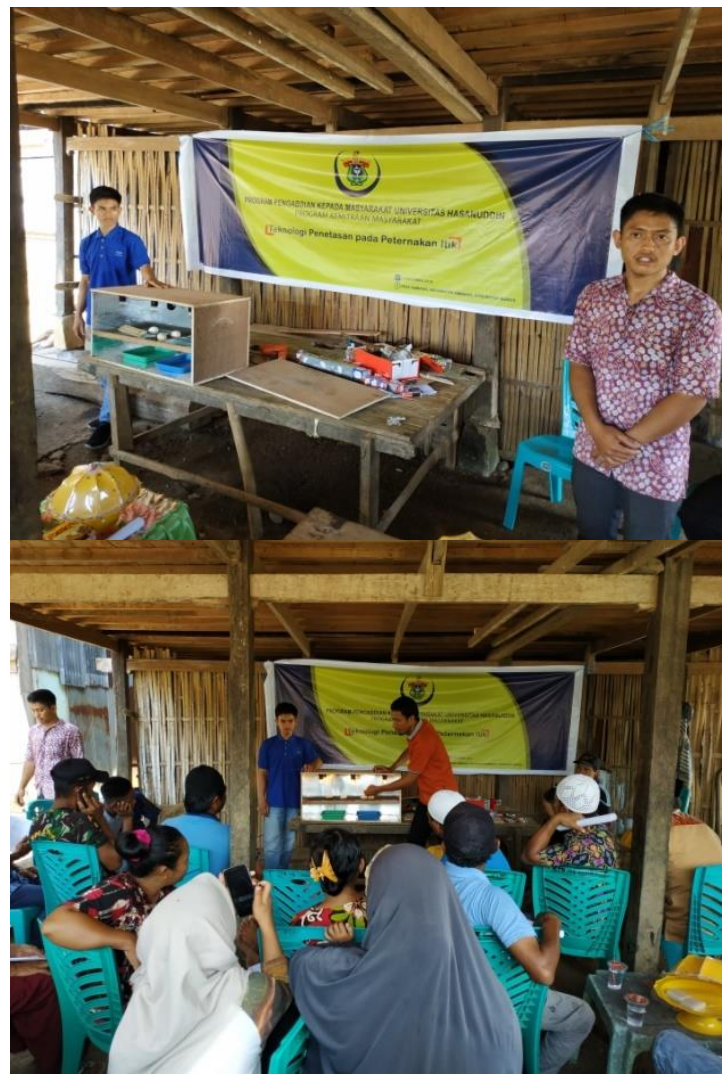

Gambar 2. Pelatihan Pengoperasian Mesin Tetas

Kegiatan selanjutnya adalah melakukan pendampingan, terutama untuk aspek adopsi penetasan dan pembesaran anak ayam pasca tetas. Unit penetasan dengan kapasitas 100 butir (Gambar 3) yang dibuat pada saat kegiatan pelatihan, dioperasikan di salah satu rumah peternak yang dinilai memiliki kemampuan lebih untuk melakukan kegiatan penetasan dan dapat menjadi contoh bagi peternak lainnya. Selama proses penetasan tahap I, daya tetas telur yang dihasilkan masih dibawah angka $60 \%$.

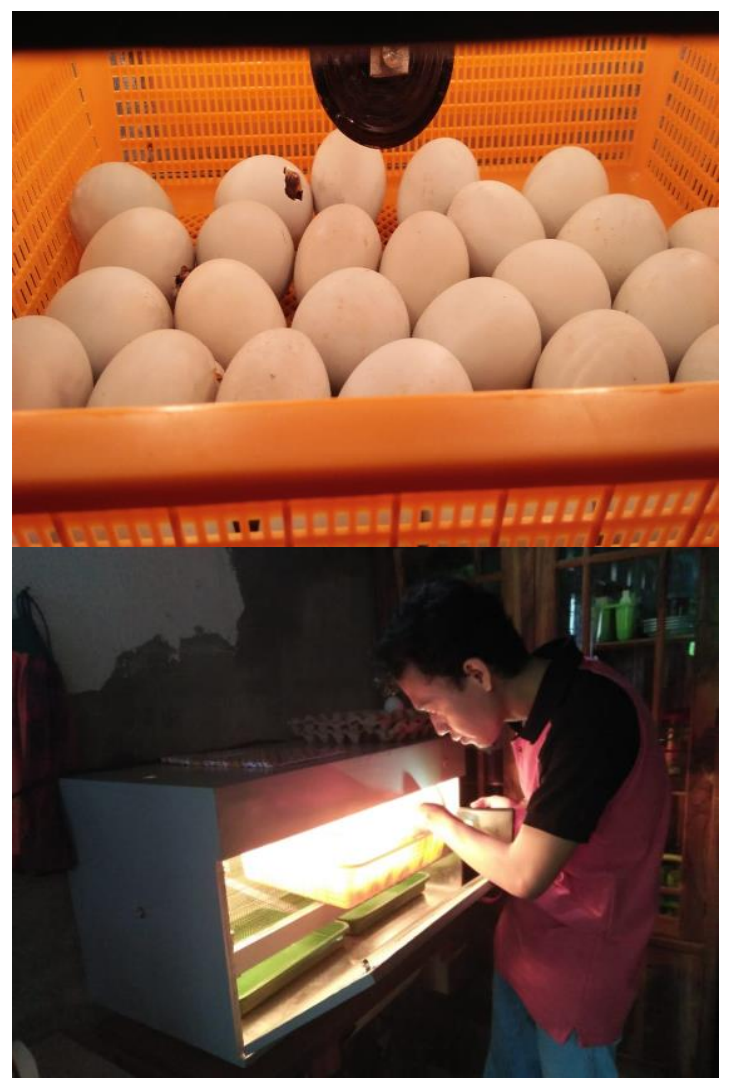

Gambar 3. Pendampingan Proses Penetasan Dengan Menggunakan Mesin Tetas

Pada kegiatan pelatihan ini, selain leaflet dan meteri pelatihan yang dibagikan ke peserta, juga diberikan satu unit mesin tetas sederhana yang digunakan bersama selama proses pelatihan dan pendampingan. Banyaknya peternak yang mengajukan pertanyaan selama materi berlangsung menunjukkan bahwa materi pelatihan yang dibawakan merupakan materi yang sesuai dengan permasalahan yang petenak hadapi selama ini. Untuk itu, narasumber pada kegiatan pelatihan tersebut juga berupaya memilih paket teknologi yang lebih mudah dan sesuai untuk diterapkan pada kondisi wilayah di lingkungan peternak di desa mitra.

\section{KESIMPULAN}

Program pengabdian ini merupakan kegiatan yang diharapkan dapat merubah pola pikir peternak itik untuk mampu menerapkan teknologi tepat guna yang akan meningkatkan pendapatan peternak sehingga kesejahteraan peternak meningkat. Diperlukan pendampingan secara rutin agar teknologi yang telah diberikan bersama fasilitas penunjangnya, bermanfaat dan menjadi contoh bagi peternak lainnya untuk meningkatkan pendapatan dan kesejahteraan serta populasi ternak itik di daerah mitra. 


\section{UCAPAN TERIMA KASIH}

Kegiatan Pengabdian Program Kemitraan Masyarakat teknologi penetasan pada peternak itik ini mendapatkan pendanaan dari BOPTN Universitas Hasanuddin tahun 2019. Ucapan terima kasih ditujukan kepada Lembaga Penelitian dan Pengabdian Masyarakat Universitas Hasanuddin yang telah mengorganisir pendanaan untuk kegiatan ini. Ucapan terima kasih juga ditujukan kepada masyarakat dan anggota kelompok mitra serta semua pihak yang telah berpartisipasi aktif atas bantuan dan kerjasamanya selama kegiatan berlangsung, sehingga dapat berjalan dengan lancar.

\section{DAFTAR PUSTAKA}

[1]. Shanawany. 1994. Quail Production Systems. FAO of The United Nations. Rome

[2]. Daulay, A. H., S. Aris, dan A. Salim. 2008. Pengaruh umur dan frekuensi pemutaran terhadap daya tetas dan mortalitas telur ayam Arab (Gallus turticus). Jurnal Agribisnis Peternakan 1: 6-10.

[3]. Mardikanto, T. 2009. Sistem Penyuluhan Pertanian di Indonesia. UNS Press.

[4]. Paimin, F.B. 1996. Membuat mengelola mesin tetas. PT Penebar Swadaya, Jakarta 